\title{
LA CRISIS DE IDENTIDAD GENÉ- RICA EN EL ADOLESCENTE Y EL HOMOSEXUALISMO
}

\author{
M arco A. Leal G óes, Ps. \\ Director de Educación y M inisterio de la Familia \\ U nión N orte Brasileña de la I glesia A dventista del $7^{\circ} \mathrm{D}$ ía \\ marco.goes@adventistas.org.br
}

Fecha de recepción: Junio 2012 Fecha de aceptación y versión final: Julio 2012

La dificultad de explicación para algunos comportamientos que ocurren en una determinada fase del desarrollo, ha atemorizado a algunas personas y generado preocupación en otras. Sin embargo, existe la necesidad de profundizar los estudios y debates en torno al desarrollo humano en la sociedad, especialmente en lo relativo a conductas que se apartan de lo que convencionalmente se está acostumbrado, entre ellas, las conductas homosexuales. La investigacion discute los desafíos queel adolescente presenta en relación al homosexualismo y cómo enfrentarlos.

Palabras clave: H omosexualismo, familia, crisis de identidad, género. 
Entonces dijo 'E lohim: $\mathrm{H}$ agamos al hombre a nuestra imagen, conforme a nuestra semejanza... Y creó 'E lohim al hombre a su imagen, a imagen de 'E lohim lo creó, macho y hembra los cré.. Luego 'E lohim los bendijo; y les dijo 'E lohim: F ructificad y multiplicaos, llenad la tierra y sojuzgadla.

G énesis 1:26-28

\section{Introducción}

La sociedad actual ha dado gran importancia al tema de la homosexualidad, principalmente por el aumento de adeptos a movimientos gay cuyo objetivo es implantar la identidad homosexual como un comportamiento normal, y como tal, ser aceptado por todos los sectores sociales. Los medios de comunicación se han encargado de propagar desenfrenadamente esa temática, haciéndola casi una política social, destacando el tema de manera absurda en diversos programas, específicamente en películas, teleseries y novelas.

Como la homosexualidad ha llegado a espacios antes inaccesibles, se torna inevitable e imprescindible que se abra un debate extenso y especializado con los sectores sociales que más "sufren" por la desinformación, y que son los espacios con ma- yor presencia homosexual en nuestra sociedad, destacando de manera especial las instituciones educativas.

El presente ensayo tiene como objetivo ofrecer información para elucidar la complejidad y el desconocimiento que cercan el tema y presentar ayuda a aquellos que se encuentran confundidos y vulnerables frente a la avalancha de los medios de comunicación, que en la búsqueda desenfrenada por audiencias económicas, presenta el tema, en dibujos animados 0 reality show, sin proveer a sus "clientes" una información especializada del tema. Como bien relata Springett,

En la actualidad, la homosexualidad ya no es algo oculto de la sociedad, que deba ser discutido en secreto y jamás mencionado en presencia de visitas. H oy es abiertamente discutida en la radio, TV y en la literatura. En muchos casos, incluso es defendida como un estilo de vida plenamente aceptable como la heterosexualidad e incluso hasta superior a ella. N o es raro que grupos homosexuales se unan a otros grupos de activistas sociales tales como movimientos por los derechos civiles 
y por los derechos de las mujeres, para militar a favor de su causa. ${ }^{1}$

\section{Contextualizando el desa rrollo del individuo}

El estudio del desarrollo del hombre siempre intrigó a la ciencia y, de cierta manera, siempre intrigó también al hombre.

Por ignorar su Palabra o por negar la evidencia de su poder Creador, los hombres procuran encontrar formas de explicar los orígenes de algún modo diferente. Se han propuesto muchas teorías, hoy la más popular es el evolucionismo, que afirma que

46 el azar fue el responsable de que existan la vida y la inteligencia. Alguien presentó, hace poco, la teoría de que el ser humano es simplemente la proyección de computadoras y que realmente no existe, sino que es solo creación de las computadoras de una súper raza de seres extraterrestres. $^{2}$

1 Ronald Springett, $O$ limite do prazer (Tatuí, SP: Casa Publicadora Brasileira, 2007), 7.

2 Rosalie Hafner de Zinke, La adoración: Guía de estudio de la Biblia edición para maestros / julio - septiembre 2011, trad., Rolando A. Itín (Buenos Aires: Asociación Casa Editora Sudamericana, 2011), 21.
Vivimos un intervalo de 'descubrimientos'. Los descubrimientos humanos comenzaron con la preocupación del hombre con lo que estaba "afuera" de él, así el estudio de los astros y de los fenómenos fue el centro de la búsqueda y descubrimiento, y lo que por mucho tiempo determinó la construcción del conocimiento. A hora los esfuerzos se vuelcan a fin de conocer al hombre como un ser existencial, en un momento casi concomitante somos sorprendidos por un 'descubrimiento' totalmente desconocido por un mundo humano subjetivo, como la presencia de agua en M arte.

La búsqueda del conocimiento (verdad) es una cuestión que todavía trae mucho malestar, pero es justamente ese malestar que impulsa al individuo a enfrentar varios desafíos, la ciencia está cada vez más desarrollada y trae nuevos experimentos, en fin, la humanidad busca en todo momento conocer algo nuevo, un nuevo descubrimiento, conocer otros universos, planetas, puede hasta hacer previsiones del futuro, 0 sea, el hombre conoce mucho, pero no es suficiente para agotar o limitar el conocimiento sobre sí mismo. 
El hecho de que el individuo no se conoce en plenitud, deja el suelo fértil para especulaciones, preconceptos y hasta mentiras bien formuladas sobre quién 0 qué es el ser humano. Lo encontrado en los descubrimientos internos del individuo ha sido una fuente inagotable para el estudio todavía más profundo del individuo.

Se debe partir comprendiendo que estamos frente a un ser que reúne aspectos biológicos, psicológicos, sociológicos y espirituales (biopsicosocioespiritual), filosóficos, éticos y morales. Elegiremos esteúltimo como uno de los puntos de partida para la búsqueda de la comprensión de la complejidad existente en el individuo. Este neologismo (biopsicosocioespiritual) es justificable cuando la pretensión es comprender a este ser multifacético y al mismo tiempo único.

El aspecto de mayor relevancia en este estudio será el psicológico, y más específicamente el desarrollo del individuo en la etapa de la juventud hasta la fase adulta. La atención residirá en el estudio del comportamiento adolescente y las elecciones típicas de ese período, principal- mente las que definen el papel y la identidad de cada individuo, con énfasis en la crisis de identidad genérica del adolescente y el homosexualismo.

\section{Los conflictos naturales de la adolescencia}

$\mathrm{H}$ ay un período en el desarrollo del ser humano que es confuso para el propio individuo, ese período es la adolescencia. Es tan confuso que algunos psicólogos afirman que es muy difícil señalar el límite entre lo normal y lo patológico, y que sería anormal esperar un equilibrio del sujeto en esa fase, para Knobel,

El adolescente pasa por desequilibrios e inestabilidades externas. Lo que configura una entidad semi patológica identificada como síndrome normal de la adolescencia, que es perturbada y perturbadora para el mundo adulto, pero necesaria, absolutamente necesaria, para el adolescente que, en este proceso, va a establecer su identidad, siendo éste un objetivo fundamental de este momento de la vida. ${ }^{\prime \prime}$

3 Arminda Aberastury y Mauricio Knobel, Adolescência normal (Porto Alegre: Artes Médicas, 1981), 9. 
Un análisis detallado de esa fase nos llevaría a sustentar la hipótesis de que la adolescencia puede no ser una fase natural del desarrollo humano propiamente dicho, sino un derivado de las matrices culturales, sociales y hasta económicas, que imponen al individuo un conjunto de exigencias con el carácter de "preparación" para la entrada en el mundo adulto, algo que es al mismo tiempo necesario e indeseado, pero inevitable. El individuo va a adolecer. Bock corrobora esa hipótesis de la "preparación" cuando asevera que,

E ntonces podemos considerar que la adolescencia es una fase típica del desarrollo del joven de nuestra sociedad. Eso porque una socie dad evolucionada técnicamente, - sea, industrializada, exige un período para que el joven adquie ra los conocimientos necesarios para participar de ella. ${ }^{4}$

Esta última parte de que el 'joven necesita adquirir conocimientos necesarios para participar de ella' merece recibir el énfasis de que ese conocimiento

4 Ana Maria Bock, Psicologias (São Paulo: Editora Ática, 1993), 96. involucra también el desarrollo de actitudes, preferencias y comportamientos que lo hagan ser aceptado (aspecto importantísimo para el adolescente), y para que eso ocurra, el adolescente está dispuesto a las más intensas anormalidades.

El mundo adolescente está marcado por una serie de conflictos "normales" que están intrínseca e indisolublemente ligados a esa fase.

En la psicología hay un concepto muyimportanteque se usa para entender lo que pasa con el individuo, a este concepto/ técnica se lo llama EMPATIA. Es lo mismo que colocarse en el lugar del otro. Para ello debe realizar por algunos momentos una abstracción; colocarse en el lugar del adolescente que, de la fase juvenil hasta la pre adolescencia, vivía en un mundo de papeles bien definidos y necesidades básicas satisfechas, y de un momento a otro, la vivencia de un conjunto de "pérdidas" que le causan una serie de comportamientos extraños pasan a ocurrir como un torbellino de cosas extrañas.

La pérdida del cuerpo infantil es una de ellas. El cuerpo que 
en la infancia no presentaba alteraciones tan "violentas", en la adolescencia pasa a recibir los impactos hormonales que dejan la dinámica biológica alterada en varios niveles. 0 tra pérdida es la identidad infantil que concomitantemente actúa obligando al adolescente a asumir una serie de responsabilidades que lo asustan. U na tercera pérdida muy conflictiva para el adolescente constituye la pérdida, de los padres en la infancia. Estos representan seguridad y protección y en vez de eso encuentra un feedback, [un paso atrás] en los padres que comienzan a cobrar comportamientos que antes no exigían.

Otros conflictos involucran la vida del adolescente, algunas palabras que los identifican son: aborto, ansiedad, pánico, culpa, depresión, disturbios alimentarios, disturbios del sueño, drogas, alcohol, duda espiritual, esquizofrenia, exceso de actividad, estrés del trabajo, fobia, tartamudeo, homosexualismo, sentimiento de inferioridad, conflicto con hermanos, luto, masturbación, obesidad, obsesiones, compulsiones, padres divorciados, necesidad de perdón, pornografía, presión del grupo, promis- cuidad, sexo prematrimonial, rabia, rebeldía, violencia, armas de fuego, soledad, suicidio, timidez, vicio en internet y juegos de computador, violencia en la escuela, aprobación del preuniversitario, primer empleo, sentirse rechazado, enamorar, embarazo y casamiento precoz, quién es Dios, etc. La lista es larga, la mayor parte del tiempo el adolescente lo gasta pensando e intentando resolver sus conflictos internos y externos.

Las (dis)funciones hormonales toman el cuerpo adolescente provocando una crisis de identidad genérica que amenaza destruirlo.

Para muchos adolescentes, es un momento muy difícil de entender el que les toca vivir, y si además el joven o la joven viven en un hogar cristiano donde las reglas son presentadas arbitraria y autoritariamente, los sentimientos confusos de esa fase pueden ser enormemente agravados por profundos momentos de culpa o hasta temores secre tos de castigo divino por estar sintiendo "tales cosas". Esto no quiere decir, que esos hogares tengan mayor probabilidad de formar homosexuales, el punto 
aquí es la manera de abordar la situación; comprobadamente el autoritarismo contribuye a agravar cualquier tipo de relación.

Para muchos estudiosos es plenamente aceptable como normal queal gunos adolescentes pasen por una serie de conflictos y hasta un período de "pre homosexualidad". Eso no es lo mismo que decir que en este período el joven o la joven sean homosexuales, hasta que se comporten como tales, este sentimiento y comportamiento representa psicológicamente un conflicto por establecer la identidad, y es en este contexto que la familia tiene un papel importantísimo.

\section{La construcción de la identidad sexual}

La construcción de la identidad sexual del adolescente en general es forjada dentro de un clima de intenso conflicto. En la mayoría de las veces, el conflicto más frecuente es con los padres. La familia del adolescente también está pasando por "conflictos", aquella situación de tratar con el adolescente y su mundo también es nueva y diferente, y no cuenta mucho si en la familia existe uno 0 más adolescentes, pues cada persona es de una ma nera y cada uno tiene sus particularidades en esa fase de la vida.

Los cambios que están ocurriendo (tanto en el mundo interno del adolescente, como en el ámbito de las relaciones inter familiares) traen mayor presión y cargas de incomprensión; esto lleva al adolescente a actuar con más desesperación (nadie me comprende en esta casa). Es común que los padres se sientan inseguros cuando esos comportamientos de rebelión, depresión, etc., comienzan a aparecer, esto los hace tomar dos tipos de actitudes: privar al adolescente de la libertad y/ 0 dinero, lo que la mayoría de las veces acaba agravando el conflicto. Es característico en esa fase que se manifiesten tres grandes necesidades en el mundo del adolescente: 1) Necesidad de ser respetado; 2) N ecesidad de defender una ideología y 3) La necesidad de sentirse amado por alguien que no sea de su familia (enamorado/a).

El adolescente necesita "probar" para él y para otros que es alguien. Eso es complejo y aterrador para un joven que está dando los primeros pasos de su 
desarrollo en este mundo conflictivo. Muchos estudiosos de esta fase explican la formación de la identidad adolescente anclada en dos presupuestos. El primero es la búsqueda de una uniformidad en la manera de ser quele proporcione seguridad y estima personal, por eso se le hace necesario identificarse con grupos positivos que le ayudarán en la construcción de una identidad sana. Sin embargo, también están presentes en esa fase otros presupuestos que $H$. E. Erikson lamó de identidad negativa que sería una identificación con figuras negativas, más reales. Erikson, en su libro, The Problem of Ego Identity transcribe de la siguiente manera la búsqueda de la identidad adolescente,

Es preferible ser alguien perverso, indeseable, a no ser nada. Esto constituye una de las bases de los problemas de las bandas de delincuentes, de los grupos de homosexuales, de los adeptos a las drogas, etc. $^{5}$

Todas esas situaciones generan mucho malestar en el adoles-

5 Erik Homburger Erikson, The Problem of Ego Identity (Nueva York: International Universities Press, 1956), 56. cente. En al gunos casos para huir de esa situación el adolescente adopta una "identidad fluctuante"; de pronto se comporta como un adulto, y en otro momento se comporta claramente como un niño. En esta etapa es habitual que los estilos de personalidad estén relacionados a los ambientes que frecuenta, siendo que para cada ambiente (casa, escuela, club, etc.) adopta un estilo de comportamiento diferente.

Solo que esa "fluctuación" no durará por mucho tiempo. El surgir del semen en los hombres y el comienzo de la menstruación en las mujeres son dos procesos biológicos que ocurren de manera impuesta y con una exigencia a la aceptación de la genitalidad. Estos procesos fisiológicos imponen al papel genital la procreación y la definición sexual correspondiente. Es en esta fase de "indefinición" sexual, que solemos ver comportamientos masculinos en las niñas y actitudes femeninas en niños que parece exponer una "bisexualidad" no resuelta.

La definición sexual no la determina la existencia de órganos genitales y ni la orientación sexual es una cuestión fisiológi- 
ca. Las preferencias sexuales se aprenden. En esta fase, el joven buscará la elaboración adulta de su identidad con el padre, y dependiendo del tipo de vivencia que mantuvo en la relación, podrá identificarse con los aspectos malos o buenos de la relación. Al identificarse con los aspectos buenos, ese joven podrá construir una identidad de sujeto capaz, independiente, creativo y finalmente adulto, preparándose así para usar sus órganos genitales con el fin y proposito de su existencia encaminandose a la procreación y a buscar el placer en relaciones heterosexuales.

Si la identificación estuviera

52 formada por aspectos negativos donde el joven no se siente feliz para emprender, conquistar, antes se siente frágil e incapaz identificándose con los aspectos negativos de la relación, le provocará miedo a la independencia asociado a un sentimiento de falta de preparación para enfrentar el mundo adulto y sus responsabilidades. La joven tambiên pasa por un proçeso semejante, y su identificación debería darse con la figura materna y sus atributos femeninos. Según Mauricio Knobel y Fenichel, ahí se sientan las bases del homosexualismo adolescente, entendido como un fenómeno temporario de adaptación, que puede ca- racterizarse solo por comportamientos afeminados o masculinizados, o tener o no relaciones homosexuales.

Para Les Parrott la comprensión de esta fase de definición de la identidad sexual está basada en la complejidad de las relaciones familiares,

La adolescencia es el período cuando la identidad sexual emergente se pone a prueba. La homosexualidad, de acuerdo con muchos, se debe a una profunda perturbación en las relaciones entre padres e hijos. El niño, por ejemplo, puede tener un padre distante, desinteresado y hostil, y una madre excesivamente afectuosa, posesiva y controladora. Por causa del rechazo del padre, el deseo del hijo de identificarse con la figura paterna se frustra y se planta la semilla del miedo y el deseo de intimidad con el sexo masculino. El comportamiento sofocante de la madre disminuye todavía más la probabilidad de que el niño establezca una identidad masculina completa. ${ }^{6}$

Diversas investigaciones mues-

6 Les Parrott, Adolescentes em conflito (São Paulo: Editora Vida, 2003), 227. 
tran que el modelo familiar homosexual está caracterizado por la ausencia de la figura paterna y por un dominio excesivo de la figura materna.

\section{H omosexualismo: enfermedad, disturbio u opción personal}

Se usa el término homosexualismo con el propósito de contextualizar el fenómeno al ámbito relacionado al individuo homosexual, pero también, para considerar los aspectos culturales, sociales, políticos e históricos que se interrelacionan con este asunto, y además, para localizar las discusiones para una comprensión más amplia, y así no tratar solamente el homosexualismo como homosexualidad, lo que comúnmente termina enfatizando más el aspecto (homo) sexual en detrimento de los otros aspectos que también están presentes en esa fase.

Por lo tanto, se inicia este tópico presentando conceptos de varios estudiosos sobre el homosexualismo. Springett destaca los siguientes conceptos:

$\mathrm{H}$ omosexualidad se refiere a la actividad sexual entre parejas del mismo sexo.?

$\mathrm{L}$ a definición de M aloy para ho-

7 Springett, 11. mosexual es "persona masculina o femenina, que siente en la vida adulta atracción erótica regular y casi exclusiva por miembros del mismo sexo, y que es indiferente a las relaciones sexuales con el sexo opuesto". ${ }^{8}$

Para M armor, homosexual es alguien que está motivado en la vida adulta por una definida y preferente atracción erótica por miembros del mismo sexo y que generalmente (pero no necesariamente) se involucra abiertamente con ellos en relaciones sexuales. ${ }^{9}$

Bieber caracteriza la homose xualidad como un desorden de adaptación, resultado de temores ocultos y no potencializados por el sexo opuesto. ${ }^{10}$

Barnhouse [...] Empleó la palabra homosexualidad para referirse a una adaptación adulta caracterizada por el comportamiento sexual preferente entre miembros del mismo sexo.11

D esde hace años los estudios

8 Ibíd., 12.

9 Ibíd., 20.

10 Ibíd.

11 Ibíd. 
buscan explicar el origen del homosexualismo, se utilizaron teorías psicológicas, sociológicas, postulados genéticos/ biológicos y otros para aclarar el tema y sus implicaciones. La literatura científica reciente afirma los estudios del origen de la homosexualidad en tres aspectos: los factores genéticos, las influencias hormonales 0 endócrinas y los elementos psicosociales. En cuanto a los aspectos genéticos destaco lo que afirma Springett,

A lgunos investigadores propusie ron la teoría de que la herencia, factores genéticos 0 de cromosomas, sería la causa de la homosexualidad. La hipótesis es la de que el síndrome de K linefelters, caracterizado por la presencia de un cromosoma femenino adicional, podría predisponer a algunos individuos a la homosexualidad. Basándose en esa hipótesis, algunos defienden que los homosexuales son seres femeninos en cuerpos masculinos. Sometida a examen bastante minucioso, la investigación de Lang se consideró poco convincente. West, después de examinar el material lo resumió: Se puede asegurar que el cromosoma sexual y anomalías endócrinas observados recientemente, no desempeñan un papel significati- vo en la causa de la homosexualidad. Investigaciones posteriores tampoco confirmaron los estudios de Kallman con gemelos homosexuales mono cigotos (idénticos). No todos los pares de gemelos idénticos son homosexuales como era de esperar, en el caso de que la condición fuese genética. L os estudios genéticos en general no lanzaron mucha luz sobre las causas del fenómeno homosexual. ${ }^{12}$

En relación al aspecto hormonal, A. C. Kinsey, refiriéndose al informe Wolfenden, observa que,

Los que aceptan esa interpretación suponen, sin procurar evidencia específica, que al elegir una pareja sexual, un individuo lo hace afectado por alguna facultad biológica básica. No existe ningún trabajo sobre hormonas 0 cualquier otras funciones fisiológicas del animal humano que justifique tal conclusión. ${ }^{13}$

Además de esos aspectos están los factores psicosociales. A spectos relacionados a la elección y orientación sexual y a las influencias psicosociales parecen formar el telón de fondo

12 Ibíd., 25. La cursiva es nuestra.

13 A.C. Kinsey, Sexual Behaviour in the Human Male (Philadephia: W.B. Saunders, Co., 1965), 658-59. 
para entender el homosexualismo. Basados en esos estudios, podemos afirmar que, el único hecho sobre el cual parece que se tiene un poco de seguridad es que la identificación homosexual se aprende en el proceso de crecimiento humano, casi de la misma forma como se aprenden todas las identificaciones y prácticas de la personalidad.

Para ampliar todavía más nuestra comprensión, es necesario entender la homosexualidad como un "desorden en las relaciones", que provoca consecuencias perturbadoras tales como separación de la familia, rechazo de los amigos, desprecio del mundo heterosexual, exposición a las molestias sexualmente transmisibles, tales como SIDA, tuberculosis, y hasta un período más corto de vida. Por todas esas consideraciones, decir que un adolescente en conflicto "elige" ser homosexual es inapropiado cuando se entiende el contexto de la crisis de identidad de géne ro y el homosexualismo.

\section{H omosexualismo: cómo luchar con el conflicto}

A propósito se ha dejado esta parte como la última de esta investigación. Si se siente tentado a leer primero esta parte, temo que su comprensión no será tan completa, para ello es necesario leer los textos y comentarios anteriores. Mucho de lo que se presenta aquí tiene como base el libro del Dr. James Dobson, Educando niños, ${ }^{14}$ en especial el capítulo 9 que trata de los orígenes de la homosexualidad.

El homosexualismo tiene algunas características identificadoras que pueden aparecer si se desarrolla desde muy temprano, hasta ser adoptadas por un individuo que en la fase adulta decide claramente adoptar un comportamiento homosexual. $\mathrm{H}$ ay una similitud de rasgos en el comportamiento psicológico de individuos homosexuales que se presentan en algunos como inseguridad, frustración, rebeldía y una mezcla de grandes conflictos psicológicos que incluyen ser observados durante el proceso de desarrollo. Ellos son:

- Declaraciones repetidas del deseo de ser, o insistencia de que él o ella son del otro sexo.

- En los niños, preferencia de

14 James Dobson, Educando $\mathrm{Me}$ ninos (São Paulo: Editora Mundo Cristão, 2003), 125-40. 
vestirse como nịna, o simular ropas femeninas. En las niñas, insistir en usar solo ropas masculinas estereotipadas.

- Preferencia fuerte 0 insistir en hacer papeles del otro sexo en los juegos, o fantasías persistentes de ser del otro sexo.

- Deseo intenso de participar de juegos y pasatiempos del otro sexo.

- Fuerte preferencia por compañeros de recreación de otro sexo.

Los escritos de C ory y C larck demuestran que el mundo de muchos homosexual es está compuesto de perversiones, drogas, masturbación solitaria, infidelidad, promiscuidad y frecuentar lugares peligrosos en busca de satisfacción de sus deseos homosexuales. ${ }^{15} \mathrm{M}$ eira describe así este aspecto:

No es raro que las personas que viven la experiencia del homosexualismo se refugien en vicios alimentarios para soportar las

15 Bengis Cory, Combat in the erogenous zone (New York: Knopf, 1973), 15-145; D. Clark, Loving someone gay (Milbrae, CA: Celestial Arts Publishing,1977), 1-288. presiones psicológicas. Ellas sufren. Se afligen por la opción que hicieron para si mismas. Son ridiculizadas, rechazadas, inadaptadas, marginadas. O ficializar el homosexualismo no resolverá el problema. No disminuirá el dolor. Esas personas continuarán luchando contra la naturaleza. ${ }^{16}$

El homosexualismo tiene varias maneras de presentarse, éste es uno de los factores que exigen estudio y conocimiento de causa para los que luchan con jóvenes en escuelas, internados, clubes e iglesias. Esté atento a los estilos de comportamiento y apto para ayudar a actuar cuando sea necesario e indispensable. Así, presento didácticamente el resultado del estudio de Mansell Pattison que está transcrito en Less Parrott sobre "tipos de homosexualismo", 17

1. El homosexualismo experimental normalmente se refiere a experimentos del adolescente, en grados diferentes de interacción sexual con los dos sexos. En grado menor el adolescente tiene actividad 'homoerótica',

16 Valéria Peixoto Meira, Sexualidade plena (Tatuí, SP: Casa Publicadora Brasileira, 2005), 93.

17 Parrott, 224-26. 
como por ejemplo quedar excitado al comparar órganos sexuales (que puede ocurrir en el baño de la escuela [la cursiva fue agregada]). En grado mayor la experimentación del adolescente es la relación sexual con ambos sexos. En general esa experimentación conduce a la he terosexualidad exclusiva.

2. El pánico homosexual es un fenómeno muy común en los jóvenes. El adolescente ve a una persona desnuda (del mismo sexo) en el baño después de la clase de educación física, y de repente queda excitado. Normalmente no se trata de un impulso sexual. Es una simple excitación sexual genérica por ver un cuerpo desnudo.

3. El homosexualismo situacional implica el comportamiento homosexual cuando las relaciones heterosexuales no son accesibles. Los presidios son ejemplos más comunes. El alivio sexual es la motivación principal y no hay afecto ni intimidad.

4. El homosexualismo social representa la adopción del comportamiento homosexual como parte de un papel social requerido.

5. El homosexualismo obligatorio se refiere al acuerdo de orientación sexual de algunas personas con una necesidad interna. Ellas no sienten ninguna excitación heterosexual, pero descubren una atracción homosexual. En general no sienten el menor placer en el típico galanteo adolescente, aunque mantengan excelentes relaciones sociales con el sexo opuesto. Simplemente no sienten atracción alguna. Cuando comienzan a sentir el impulso homosexual, al final de la adolescencia, quedan sorprendidas, como si no fuera su voluntad. Se sienten obligadas por sus sentimientos a corresponder al mismo sexo. Para Pattison ese modelo se refiere a la mayoría de los homosexuales.

6. El homosexualismo preferencial se da en las personas con tendencias bisexuales. Muchos homosexuales experimentan impulsos heterosexuales y practican actos heterosexual escon satisfacción. Pueden simplemente preferir 
la experiencia homosexual en vez de la heterosexual.

\section{La B iblia y la sexualidad}

En verdad éste es el tópico aglutinador de esta investigación, fue elaborado luego de haberse escrito todos los otros tópicos. Sin embargo, se reconoce las limitaciones propias de un profesional no teólogo, que trata de abordar un tema bíblico a profundidad.

Nuestra sociedad está profundamente ahogada en una cultura del sexo donde el modelo es exclusivamente la "creatividad viciada" de la mente humana. W hite llama la atención al afirmar,

Para cada privilegio legítimo y dado por Dios, Satanás sugiere una falsificación. Procura remplazar los pensamientos santos y puros con pensamientos impuros. Desea sustituir la santidad del amor matrimonial con la permisividad, la infidelidad, los excesos y la perversión; el sexo premarital, el adulterio, el animalismo dentro y fuera del matrimonio, y la homosexualidad. (M ente, carácter y personalidad. ${ }^{18}$

18 Elena G. de White, Mente, carácter y personalidad (Buenos Aires: Asociación Casa Editora Sudamericana, 1991), 1:225.
No ignoramos la caída de Sodoma debido a la corrupción de sus habitantes. A quí el profeta ha especificado los males particulares que llevaron a la inmoralidad. A hora vemos que existen en el mundo los mismos pecados que hubo en Sodoma, y que trajo sobre ella la ira de Dios, incluso su completa destrucción. ${ }^{19}$

O bserve el título de esta sección, no se presentará la homosexualidad y la Biblia, no se tratará aquí de destacar cuál es la posición de la Biblia en relación al homosexualismo, porque está expresado de manera inequívoca en diversos textos, como por ejemplo, en Génesis capítulos 1, 2, 13, 18 y 19; Exodo 20, 22 y 40; Levítico 18 y 20 ; Deuteronomio 22 y 27; Jueces 19 al 21; 10 Samuel 18 y 19; Jeremías 23; Ezequiel 16; $M$ ateo 19; $M$ arcos 10; Romanos 1 etc. Antes, se tratará de contextualizar de manera más amplia la sexualidad humana a partir del prisma bíblico, algo que abarca más que cualquier norma religiosa.

\section{Conclusión}

Antes de finalizar, se espera que la lectura ayude a entender

19 Ibíd., 238. 
algunos de los conflictos por los cuales pasan los adolescentes, en especial aquellos que están involucrados con el homosexualismo. Dios tiene un plan especial para todos sus hijos, se sabe quelas "relaciones homosexuales son antinaturales y agreden la anatomía, la fisiología, la moral y la espiritualidad", 20 también se conoce la existen cia de una gran cantidad de jóvenes que están viviendo una vida de engaño y sin esperanza. Es hora de levantar bien alto los valores bíblicos cristianos y presentar el estilo de vida que conduce a la eternidad.

Cierta vez se escuchó a un predicador decir que "la desgracia del mundo no es el ruido de los pervertidos, sino el silencio de los creyentes'. Es tiempo de hablar abiertamente sobre el poder de Diosa través de C risto y del Espíritu Santo, que actúa para tran sformar vidas de todos los que deseen su favor. Desde el punto de vista cristiano hay esperanza para aquellos que se colocan enteramente en las manos de Dios.

\section{Recomendaciones}

Las recomendaciones finales de este trabajo son:

20 Meira, 93.
1. Permita que los jóvenes vean a C risto en sus actitudes.

2. Presente a sus jóvenes a Dios en ayuno y oración.

3. Demuestre aceptación como persona. U sted puede no concordar con las actitudes y comportamientos, pero debe recordar que hay un conflicto y que muchos de los jóvenes están pidiendo auxilio.

4. Evite una confrontación, gane su confianza y muéstreles que pueden confiar en usted.

5. Refuerce los cambios positivos por muy pequeños que sean. Por ejemplo, verlos participar en actividades de su género respectivo.

6. Si fuese posible, encamine al joven con problemas a un terapeuta cristiano.

\section{B ibliografía}

A.C. K insey, Sexual Behaviour in the H uman M ale (Philadephia: W.B. Saunders, Co., 1965), 658-59. 
A berastury, Arminda y Mauricio Knobel. A dolescência normal. Porto A legre: A rtes M édicas, 1981.

A rterburn, Stephen. A batalha de todo adolescente. São Paulo: Editora. M undo C ristão, 2007.

Bock, A na M aria. Psicologias. São Paulo, Editora À tica. 1983.

Clark, D. L oving someone gay. M ilbrae, CA: Celestial A rts Publishing, 1977.

Cory, I. B engis. Combat in the erogenous zone. N ew York: K nopf, 1973.

Declaraciones, orientaciones y otros documentos. Buenos A ires: A sociación Casa Editora Sudamericana, 2005.

Dobson, James. E ducando M eninos. São Paulo: E ditora M undo C ristão, 2003.

Gallagher, Steve. No altar da idolatria sexual. Rio de Janeiro: G raça E ditorial, 2003. $\mathrm{H}$ abenicht, Donna J. Diez valores cristianos que todo niño debería conocer. Buenos
Aires: A sociación Casa Editora Sudamericana, 2006.

$\mathrm{H}$ afner de Zinke, Rosalie. La adoración: G uía de estudio de la Biblia edición para maestros / julio - septiembre 2011. Traducido por Rolando A . Itín. Buenos A ires: A sociación Casa E ditora Sudamericana, 2011.

$\mathrm{H}$ omburger E rikson, E rik. The Problem of $\mathrm{E} g \mathrm{o}$ I dentity. Nueva York: International U niversities Press, 1956.

Meira, Valéria Peixoto. Sexualidade plena. Tatuí, SP: Casa Publicadora Brasileira, 2005.

Parrott, Les. A dolescentes em conflito. São Paulo: Editora Vida, 2003.

Santa Biblia. Versión Reina Valera Revisada, 1960.

Springett, Ronald. 0 limite do prazer. Tatuí, SP: Casa Publicadora B rasileira, 2007.

W hite, Elena $G$. de. M ente, Carácter y Personalidad. Volumen 1. Buenos Aires: A sociación Casa E ditora Sudamericana, 1991. 